\title{
Preservation Effect of Crude Fig Fruit Filtrate (Ficus carica L) Added In to Tris Egg Yolk Based Extender on Capacitating, Acrosome and Fertility of Half Blood Boer Buck Spermatozoa
}

\author{
Lalu Ahmad Zaenuri ${ }^{* 1}$, Trinil Susilawati ${ }^{2}$, Sri Wahyuningsih ${ }^{3}$, \\ Sutiman Bambang Sumitro ${ }^{4}$ \\ ${ }^{I}$ Department of Animal Production, Faculty of Animal Husbandry, Mataram University, Pendidikan Street No. \\ 62, Mataram 83114, West Nusa Tenggara, Indonesia. \\ ${ }^{2,3}$ Department of Animal Production, Faculty of Animal Husbandry, Brawijaya University, Veteran Street \\ 65145, Malang, East Java, Indonesia. \\ ${ }^{4}$ Department of Biology, Faculty of Sciences, Brawijaya University, Veteran Street 65145, Malang, East Java, \\ Indonesia.
}

\begin{abstract}
This research was conducted to know the effect of additional crude filtratet of fig fruit (CF3) into tris egg yolk (TEY) based extender on sperm progressively motile, plasma membrane integrity, incapacitation, intact acrosome and fertility of half blooded Boer buck liquid semen. Ten ejaculates were collected by artificial vagina every four days. The collected semen was divided into four aliquots in accordance to the treatments extender $(0 \%, 4 \%, 5 \%$ and $\%$ CF3 in TEY based extender, $v / v$, respectively). The overall percentage of progressively motile sperm were significantly higher $(P<0.05)$ in $T E Y+6 \%$ CF3 as compared to control and 4\% CF3 but was not significantly different as compared to 5\% CF3. The overall percentages of sperm with intact plasma membrane was significantly higher $(P<0.05)$ in TEY based extender $+6 \% C F 3$ as compared to the control, $4 \%$ and $5 \%$ CF3. The percentage difference between the incapacitated spermatozoa were significantly higher $(P<0.05)$ for both in $5 \%$ and $6 \%$ CF3 since 0 to 96 hours stored at $5^{\circ} \mathrm{C}$ as compared to control and 4\%. The difference between the overall mean percentages of spermatozoa with intact acrosome in $T E Y$ based extender incorporated with $5 \%$ and $6 \%$ CF3 were significantly higher $(P<0.05)$ than control and $4 \%$ CF3. Pregnancy rates to AI using only preserved semen at $5^{\circ} \mathrm{C}$ for 96 hours, extended in TEY based extender + 6\% CF3 was 44.68\%. It is concluded that additional CF3 into TEY based extender increased preservation ability of extender in liquid form of buck semen up to 96 hours at $5^{\circ} \mathrm{C}$ in TEY $+6 \% \mathrm{CF} 3$.
\end{abstract}

Keywords: fig fruit extract, spermatozoa, incapacitation, acrosome, pregnancy, buck.

\section{INTRODUCTION (11 BOLD)}

Cross breeding program has led to a remarkable increase in genetic improvement and production of goat, because its long terms advantages is more than to change its environment such as nutrition (1;2). In addition, cross breeding will be more efficient by implementing artificial insemination (AI). However, effort of AI has been subject to large variation due to several factors. Among them were genetic potential of buck itself, physical status of the does, semen preparation technique and skillful of AI technicians (3).

Liquid semen has many advantages in practice, such as semen preparation technique which is easy and low cost. However, liquid semen has also many disadvantages including spermatozoa lifeless is quicker than frozen semen. Therefore, if motile sperm in liquid semen can be preserved up to 48 hours, outcome of intra cervical AI using liquid semen could increase significantly $(4 ; 5)$. In fact, no extender is able to preserve liquid semen for longer than $2-3$ days without decreasing its fertility, especially in goat and sheep (6).

Since fig fruit (Ficuscarica Linn)is rich sources of non-enzymatic antioxidant and other nutrients that were greatly beneficial to improve extender quality, crude extract of the fruit has been high prospectus for a future additive of buck semen extender due to some reasons. $\alpha$-tocoferol and $\alpha$-tocoferol acetate identified at the same amount in all part of fig fruit (7). Total tocoferol, $\alpha$-tocoferol, total fenol, Vitamin $\mathrm{C}, \mathrm{Cu}$ and $\mathrm{Mg}(\mathrm{mg} / 100$ g) were $20.40,0.81,266.34,181.50,0.15$ and 223.53 , respectively. $\beta$-carotene $0.46(\mu / 100 \mathrm{~g})$, fructose, glucose, carbohydrate, protein and $\mathrm{Ca}(\mathrm{mg} / 100 \mathrm{~g})$ were $18.20,17.58,24.27,1.27$ and $44.00(8), \mathrm{Fe}$, Sodium and Potasium were $0.6-4.09 \mathrm{mg}, 2.0 \mathrm{mg}$ and $194 \mathrm{mg}$ in fresh fig fruit, respectively (9).

There is a lack of publication on the use of fig fruit extract as an exogenous antioxidant for goat semen extender. However, to the best of our knowledge, there are two previous reports in usage of crude filtrate of fig fruit (CF3) as supplement for buck semen extender. The first study has been carried out to find out an extender which could preserve progressively motile sperm up to 144 hours at $5^{\circ} \mathrm{C}$. It was indicated that a promising result of additional crude extract of Ficusglumerata Robb in tris egg yolk based extender (10). Second, additional crude extract of Ficuscarica Linn in the same based extender and preservation time at $5^{\circ} \mathrm{C}$ also showsa positive 
result on progressive motile sperm, viability, intact plasma membrane and normal sperms (8). Sperm concentration in both experiments was $75 \times 10^{6} / \mathrm{ml}$.

The aim of the present research was to study the effect of additional crude filtrate of fig fruit (Ficuscarica Linn) into tris egg yolk based extender after storage in liquid form at $5^{\circ} \mathrm{C}$ on the percentages of progressively motile sperm, intact plasma membrane, sperm incapacitating, intact acrosome and in vivo fertility of half blood Boer buck spermatozoa.

\subsection{Semen extenders}

\section{MATERIAL AND MeThODS}

Based extender preparation will be explained through the following process. First, weight $3.634 \mathrm{~g}$ tris (hydromethyl) aminomethane (Sigma, USA), $2.7 \mathrm{~g}$ citric acid (monohydrate) (Merck, German) and $0.05 \mathrm{~g}$ fructose (Merk, German), diluted in distilled water up to $100 \mathrm{ml}$, homogenized by magnetic steering while boiled on hot plate up to $97^{\circ} \mathrm{C}$. After cooling to $37^{\circ} \mathrm{C}$, then mixed it with $0.06 \mathrm{~g}$ sodium penicillin $\mathrm{G}$ (Wonder, Japan) and $0.1 \mathrm{~g}$ streptomycin (Wonder, Japan) and homogenized by magnetic steering then called as buffer extender. Second, dried $2.5 \%$ of buffer extender and replaced it by chicken egg yolk at the same volume (v/v) (11). The extender then called tris egg yolk based extender (TEY). Third, crude filtrate of fig fruit (CF3) preparation as mention in Figure 1 (8). Finally, preparation of treatments extender in brief, filled in each of 4 glass tubes with $3 \mathrm{ml}$ of TEY based extender. Dried $0 \%$ (control), 4\%, 5\% and 6\% of TEY based extender then replaced it with CF3 at the same volume (v/v) (8), respectively.

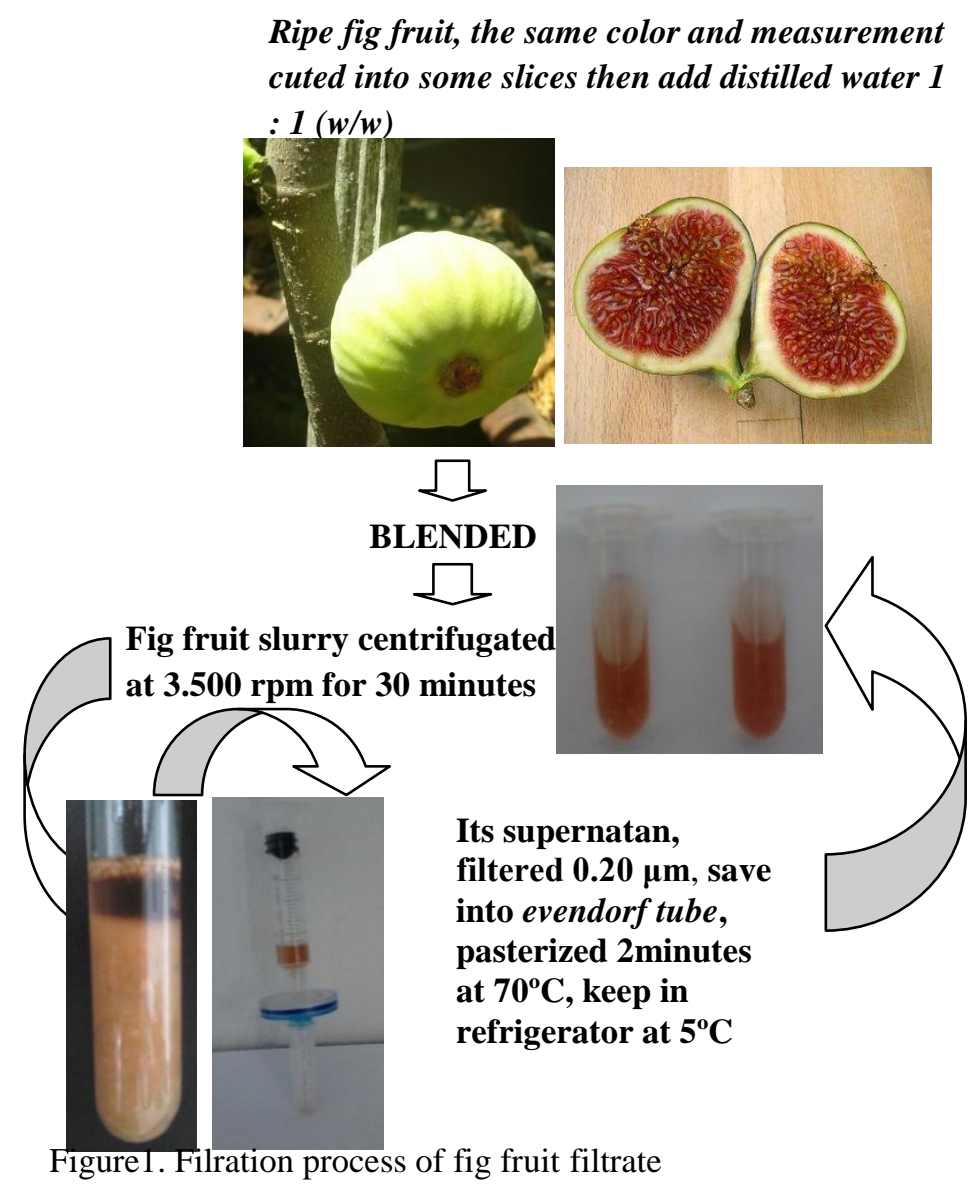

\subsection{Semen extended and preservation}

Ten ejaculates from a half blooded Boer buck were routinely collected by artificial vagina every 4 days. Sperm concentration per treatment was $300 \times 10^{6} / \mathrm{ml}$ as counted by following equation (11).

Each aliquot of semen was slowly added by one half of experimental extender. The other half was added 20 minutes later to minimize osmotic shock (12). To minimize cold shock, those four liquid experimental semen were placed into a $20 \mathrm{ml}$ beacker glass containing $50 \mathrm{ml}$ water at $10-21^{\circ} \mathrm{C}$ then keep it in refrigerator. The temperature of liquid semen will decrease gradually to $5^{\circ} \mathrm{C}$ within 2 hours (13). 
Preservation Effect of Crude Fig Fruit Filtrate (Ficus carica L) Added Into Tris Egg Yolk...

Dilution freq $=\frac{\% \text { sperm motility } \mathrm{x} \text { semen volume }}{300 \times 10^{6}}=\mathbf{X}$

If fresh semen volume is $1 \mathrm{ml}$. then $1 / X=x \mathrm{ml}$ (fresh semen) diluted in $1 \mathrm{ml}$ dilutions.

Thus, the last sperm concentration would be $300 \times 10^{6} / \mathrm{ml}$.

\subsection{Sperma evaluation}

Sperm evaluation was performed at $0,24,48,72$ and 96 post extended and stored at $5^{\circ} \mathrm{C}$. Semen sample was placed on a pre-warmed glass slide and cover with a slipped cover. Visual progressively motile sperm was assed at $37^{\circ} \mathrm{C}$ using phase contrast microscope at 400 magnificent on closed circuit monitor (14). Plasma membrane integrity was evaluated by hypo osmotic $(150 \mathrm{mosm} / \mathrm{L})$ swelling test (HOST). The HOS solution contained $0.37 \mathrm{~g}$ tri-sodium citrate dehydrate (Merck, German) and $1.35 \mathrm{~g}$ fructose (Riedel-DeHaen, Switzerland), dissolved in $100 \mathrm{ml}$ distilled water, $50 \mu \mathrm{l}$ of liquid semen sample diluted in $500 \mu \mathrm{l}$ HOST solution, then incubated for 1 hour at $37^{\circ} \mathrm{C}$. A drop of diluted semen sample is placed on a clean sterilized dry glass slide and coverdit with a cover slip. 200 sperms were counted in some fields under phase contrast microscope (Olympus, BX40, 400 magnificent) and percentages of sperm having coiled tails can be determined (15).

Intact acrosome was evaluated using FITC con A staining method. For this purpose, semen samples were fixed in $4 \%$ formal dehyde $(1: 1)$ in a glass tube wrapped in aluminium foil, then vortex for 10 seconds. Furthermore, washed that sample 3 times: first, with $3 \mathrm{ml}$ of PBS Dulbecco's solution and centrifugated for 10 minutes at 1,500 rpm. Discard the supernatant, the sediment was stained by $0.1 \mathrm{ml}$ of FITC con A containing 10 $\mu \mathrm{g} / \mathrm{ml}$ in PBS Dulbecco's, keep at room temperature for 25 minutes. The second and third washing were done as the same procedure as was in the first. Supernatant was discarded and a drop of the sediment was taken by micro pipette and placed on a clean dry glass slide, three drop of $90 \%$ glycerol were placed on the top of sediment sample then mixed and homogenized by the tip of micro pipette, then covered with a glass cover and press gently with tissue. Glue the edge of the glass cover using cutex. Flow labs slides were observed using epifluoresence microscope (Carl Zeis, German) with excitation B (490 nm $-525 \mathrm{~nm}$ emission) to identify the fluorescent in spermatozoa as a result of FITC Con A staining. All processing is done in dark room (Nishikawa, 1997 adapted by Susilawati (16).

Capacitating state assessment performed by Chlortetracycline (CTC) staining. For this purpose, 1) $10 \mathrm{~mL}$ of liquid semen sample mixed with $45 \mathrm{~mL} \mathrm{CTC}$ stain in eppendorf tubes that had been wrapped in aluminium foil then vortex for 1 minute. Furthermore, add $8 \mathrm{~mL}$ CTCfixative and re vortex for another 1 minute. 2) Take $10 \mathrm{~mL}$ of solution as mention in point 1 using a micro pipette and dropped on the dry clean object glass, mixed the ample with $10 \mathrm{~mL}$ of DABCO solution on it and homogenized by the tip of micro pipette, then cover with a glass cover and press gently with tissue. Glue the edge of the covered glass using cutex, 3) sperm capacitating state evaluated by epi-fluoresence microscope (Carl Zeis, German) using ultraviolet light source, 4) there were three different fluorescence staining of spermatozoa which can be identified with CTC: a) fluorescence will be distributed evenly to all parts of the sperm head, b) fluorescence will be concentrated on the post-acrosomal region and c) fluorescence will be concentrated in the acrosomal region. If the entire head of sperm was brightly colored it means that the sperm was incapacitated $(16 ; 17)$.

\subsection{Estrus Synchronization and Artificial Insemination (AI)}

Cycle of estrus was synchronized by the insertion of intravaginal progesterone impregnated sponges (45 mg flurogestone acetate, Chrono-gest ${ }^{\circledR}$, Intervet) for 12 days. Artificial insemination (AI) was carried out by an experienced technician. The does were inseminated by an insemination pipette using speculum with attached light source, liquid semen was deposited in the entrance of the cervic as described by Anderson et al. (18), fixed time at 48 to 50 hours after sponge's withdrawal. Result of in vivo fertilization presented in the percentages of pregnant does according to Kukovicset al. (19) that pregnancy rate $=$ Number of kidding/number of AI.

\subsection{Statistical analysis}

The statistical significance of the result was evaluated by a two way completely randomized block design, differences between means were analyzed by Duncan test (20). Data were analyzed by analysis of variance (ANOVA) using CoStat for windows statistical software (Version 6.303). Result are presented as Mean \pm SEM. Probability $(\mathrm{P}<0.05)$ considered significantly different.

\section{RESUlT}

The mean initial characteristics of half blooded Boer buck fresh semen from 10 ejaculates used in this study such as volume, color, $\mathrm{pH}$, mass wave, motility and sperm concentration were $1.41 \mathrm{ml}$, milky white, 7.03 , $+++, 77 \%, 3.293 \times 10^{7} / \mathrm{ml}$, respectively. 
Significance for the effects of additional of fig fruit (CF3) into tris egg yolk base extender (TEY), preserving time and stored at $5^{\circ} \mathrm{C}$ on progressively motile sperm and intact plasma membrane are shown in Table1. Extender and preserving time affected progressively motile sperm and intact plasma membrane. As shown in Table 1, the overall percentage of progressively motile sperm were significantly higher $(\mathrm{P}<0.05)$ in $\mathrm{TEY}+6 \% \mathrm{CF} 3$ extender as compared to control and $4 \% \mathrm{CF} 3$ but was not significantly different as compared to $5 \% \mathrm{CF} 3$. In addition, the overall percentages of sperm with intact plasma membrane was significantly higher $(\mathrm{P}<0.05)$ in TEY based extender $+6 \% \mathrm{CF} 3$ as compared to the control, $4 \%$ and $5 \% \mathrm{CF} 3$.

Table 2 indicates the mean and overall percentages means of both incapacitated sperm and intact acrosome at each time of measurement and different level of CF3 added in TEY based extender, respectively. The different between the percentages of incapacitated spermatozoa were significantly higher $(\mathrm{P}<0.05)$ for both in 5\% and $6 \% \mathrm{CF} 3$ since 0 to 96 hours stored at $5^{\circ} \mathrm{C}$ as compared to control and $4 \%$. In addition, the difference between the overall mean percentages of spermatozoa with intact acrosome in TEY based extender incorporated with $5 \%$ and $6 \% \mathrm{CF} 3$ were significantly higher $(\mathrm{P}<0.05)$ as compared to the control and $4 \% \mathrm{CF} 3$. However, the mean percentages of intact acrosome in control extender were constantly lower $(\mathrm{P}>0.05)$ as compared to extender with the inclusion of CF3. Sperm with intact acrosome and acrosome damage as illustrated in Figure 2.

Achieved pregnancy rates to AI using only preserved semen at $5^{\circ} \mathrm{C}$ for 96 hours, extended in TEY based extender $+6 \%$ CF3 was $44.68 \%$.

Tabel 1. Effect of additional CF3 into TEY based extender on Percentage progressively motile and live sperm in plasma membrane integrity and normal sperm in a different preserving time $5^{\circ} \mathrm{C}$

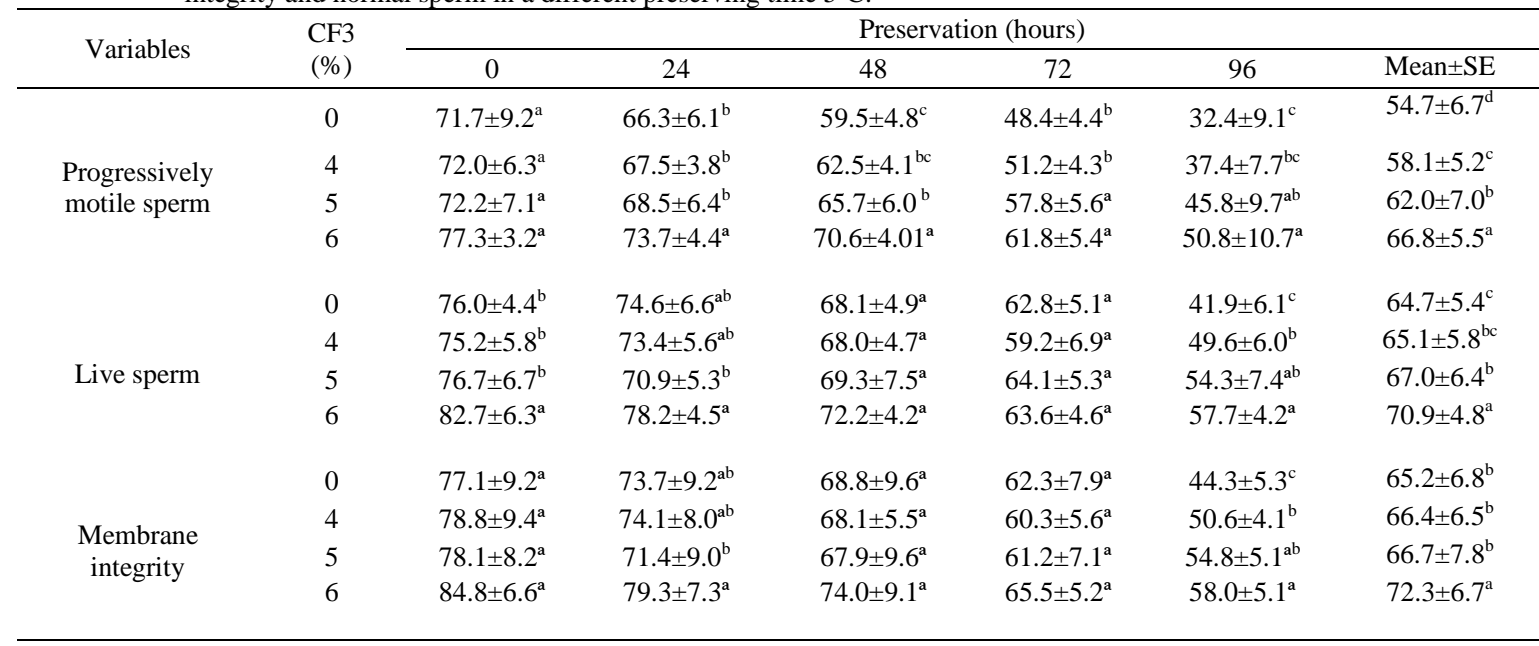

The values in the same column with different superscripts differ significantly $(\mathrm{P}<0.05)$

Tabel 2. Effect of additional CF3 into TEY based extender on Percentage of Incapacitated and Intact Acrosome in a different preserving time at $5^{\circ} \mathrm{C}$

\begin{tabular}{|c|c|c|c|c|c|c|c|}
\hline \multirow{2}{*}{ Parameters } & \multirow{2}{*}{$\begin{array}{l}\text { CF3 } \\
(\%)\end{array}$} & \multicolumn{6}{|c|}{ Preservation (hours) } \\
\hline & & 0 & 24 & 48 & 72 & 96 & Mean \pm SD \\
\hline \multirow{4}{*}{ Incapacitated } & 0 & $42.2 \pm 6.9^{b}$ & $34.6 \pm 7.5^{b}$ & $27.8 \pm 7.1^{b}$ & $19.9 \pm 5.0^{\mathrm{b}}$ & $11.75 \pm 2.6^{b}$ & $27.3 \pm 5.8^{\mathrm{d}}$ \\
\hline & 4 & $44.4 \pm 7.9^{\mathrm{b}}$ & $35.8 \pm 6.7^{\mathrm{b}}$ & $33.4 \pm 6.1^{\mathrm{b}}$ & $22.9 \pm 3.9^{\mathrm{b}}$ & $16.0 \pm 4.7^{\mathrm{b}}$ & $30.5 \pm 5.8 \mathrm{c}$ \\
\hline & 5 & $53.9 \pm 7.0^{\mathrm{a}}$ & $47.6 \pm 6.6^{\mathrm{a}}$ & $40.5 \pm 6.2^{\mathrm{a}}$ & $32.9 \pm 4.0^{\mathrm{a}}$ & $22.8 \pm 7.2^{\mathrm{a}}$ & $39.6 \pm 6.2^{b}$ \\
\hline & 6 & $56.9 \pm 8.5^{\mathrm{a}}$ & $49.3 \pm 7.9^{\mathrm{a}}$ & $42.1 \pm 6.3^{\mathrm{a}}$ & $33.8 \pm 5.9^{\mathrm{a}}$ & $27.9 \pm 7.4^{\mathrm{a}}$ & $42.0 \pm 7.2^{\mathrm{a}}$ \\
\hline \multirow{4}{*}{ Intact acrosome } & 0 & $51.5 \pm 4.78^{b}$ & $39.2 \pm 5.8^{\mathrm{c}}$ & $38.75 \pm 5.3^{\mathrm{b}}$ & $26.4 \pm 7.1^{\mathrm{b}}$ & $14.7 \pm 3.1^{\mathrm{b}}$ & $34.1 \pm 5.2^{\mathrm{c}}$ \\
\hline & 4 & $53.4 \pm 5.4^{\mathrm{ab}}$ & $40.7 \pm 6.6^{\mathrm{c}}$ & $39.8 \pm 4.8^{\mathrm{ab}}$ & $26.2 \pm 5.6^{\mathrm{b}}$ & $18.8 \pm 5.9^{\mathrm{b}}$ & $35.8 \pm 5.6^{\mathrm{c}}$ \\
\hline & 5 & $54.7 \pm 6.6^{\mathrm{ab}}$ & $47.2 \pm 3.6^{\mathrm{b}}$ & $42.9 \pm 4.7^{\mathrm{ab}}$ & $34.0 \pm 4.7^{\mathrm{a}}$ & $24.2 \pm 6.5^{\mathrm{a}}$ & $40.6 \pm 5.2^{\mathrm{b}}$ \\
\hline & 6 & $57.5 \pm 5.6^{\mathrm{a}}$ & $52.1 \pm 4.8^{\mathrm{a}}$ & $43.3 \pm 4.9^{\mathrm{a}}$ & $34.6 \pm 4.7^{\mathrm{a}}$ & $26.6 \pm 5.1^{\mathrm{a}}$ & $42.8 \pm 5.0^{\mathrm{a}}$ \\
\hline
\end{tabular}

The values in the same column with different superscripts differ significantly $(\mathrm{P}<0.05)$ 
Preservation Effect of Crude Fig Fruit Filtrate (Ficus carica L) Added Into Tris Egg Yolk...
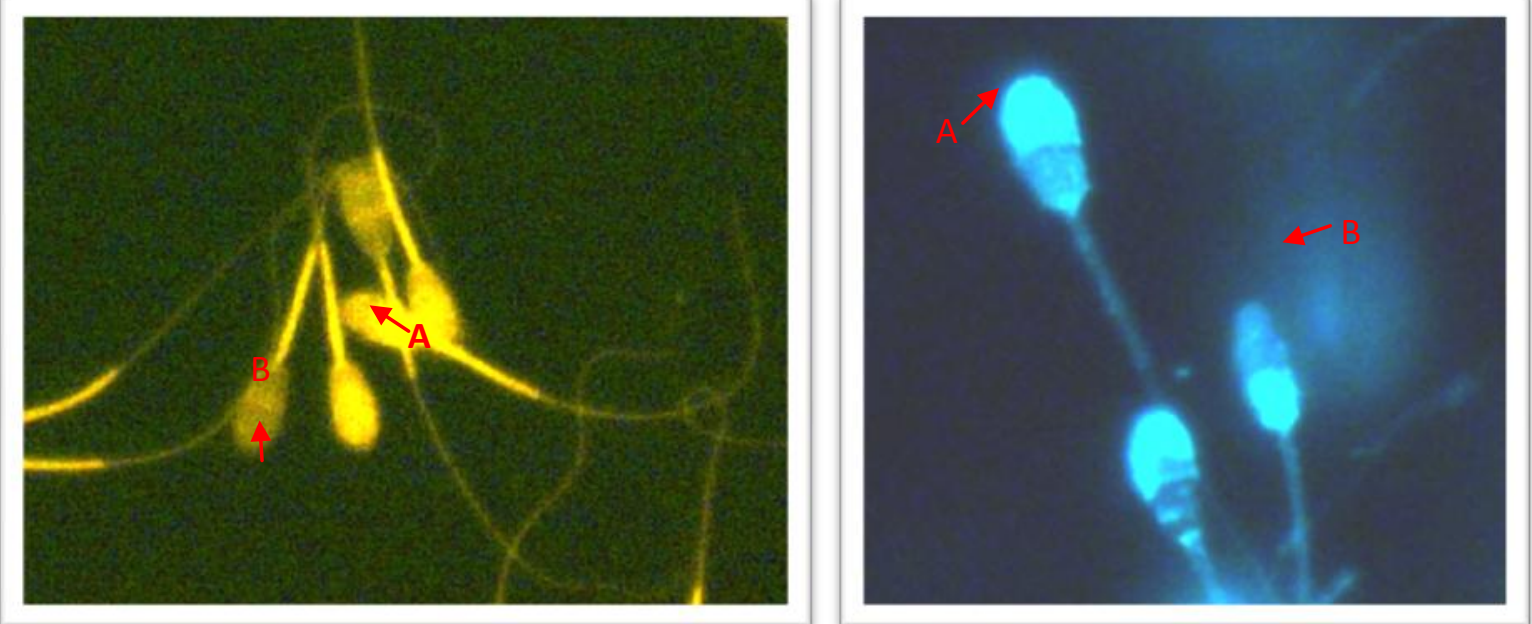

Figure 2. A. incapacitated sperm, B. capacitated sperm (Left). A. acrosome intact, B. acrosome reaction with FITC Con A staining and observed by epifluorescence microscope (Right).

$6.4-7.02$ if collected by artificial vagina (22). Appropriate sperm concentration of fresh semen for further processing should be $3 \times 10^{9} / \mathrm{ml}(23)$.

Qualified semen extender is a main course to be able to preserved maximum fertilization potential of spermatozoa (24). To the best of our knowledge, there were only two publish data on the effect of fig fruit extract into any semen extender and it effectiveness to preserve semen quality $(8 ; 10)$. Therefore, the finding in this study supports an effort to establish a proven extender not only in terms of prolong preserving time but also increased pregnancy rates.

In the present research, an overall percentage of progressively motile sperm on half blooded Boer buck was higher as compared to some previous research. Sperm motility of Sirohi buck in tris $+5 \%$ glycerol and 3.5 $\mathrm{mM}$ vitamin $\mathrm{E}$ or $3 \mathrm{mM}$ vitamin $\mathrm{C}$ extenders at 96 hours post preservation at $5^{\circ} \mathrm{C}$ were $28 \pm 4.89$ and $43 \pm 8.15$ (25). The overall sperm motility at 27 hours post extended with $70 \%$ based extender $(10 \mathrm{~g}$ sodium citrate $+30 \%$ glycine) $+30 \%$ egg yolk were noted $15 \%$ or $17 \%$ if extended with $90 \%$ based extender (45 g glucose $+6 \mathrm{~g}$ glycine) $+10 \mathrm{ml}$ egg yolk (26). Post thawing motility of Alpin buck extended with tris $+0.1 \mathrm{ml}$ and $1.0 \mathrm{mM}$ vitamin $\mathrm{E}$ were $44.26 \pm 1.8$ and $50.62 \pm 0.18$ (27). in addition, the present result was in line with reports of Zaenuri et al. $(8 ; 10)$ that $6 \%$ CF3 (Ficusglumerata Robb and Ficuscarica Linn) recorded the highest progressively motile sperm at 96 hours post extended and keep at $5^{\circ} \mathrm{C}$, respectively.

The high percentages of progressively motile sperm in this study might be led by low concentration of MDA. MDA $(\mathrm{ng} / \mathrm{mL})$ concentration on TEY based extender $+0 \%, 4 \%, 5 \%$ and $6 \%$ CF3 were decreased from 64.0, 54.0, 51.5, 49.0 at 0 hour pre mixing with semen to 56.5, 51.5, 49.0, 46.5 and 39.0, 39.6, 36.5, 36.5 at 72 and 96 hours and preserved at $5^{\circ} \mathrm{C}$. Therefore, increasing oxidative stress and reactive oxygen species (ROS) will not be increased because of additional CF3 into TEY based extender, mirrored by decreasing concentration of MDA (8). This result is matched with Hsieh et al. (28) that, MDA concentration is an indicator to predict liquid sperm quality because MDA concentration has a negative correlation with progressively motile sperm.

The average percentages of intact plasma membrane obtained from this study was higher than two previous researches with the same extender as explained before, Anghel et al. (27) reported, the percentages of plasma membrane integrity of Alpin buck spermatozoa were $43.15 \pm 1.61$ and $49.35 \pm 1.30$, respectively. In

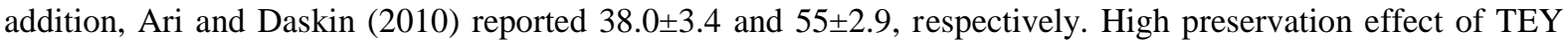
based extender incorporated with CF3 obtained in this study is likely due to synergetic action of nutrients ingredients of buck semen, TEY based extender and CF3. Micronutrients found in fig fruit included antioxidant $(\mathrm{mg} / 100 \mathrm{~g})$ such as total tocoferol (20.40), $\alpha$-tocoferol $(0.81)$, total fenol (266.34), vitamin $\mathrm{C}(181.50)$ and $\beta$ carotene $(0.46 / 100 \mathrm{~g})$, mineral such as $\mathrm{Cu}(0.15 / 100 \mathrm{~g}), \mathrm{Mg}(223.53 / 100 \mathrm{~g})$ and $\mathrm{Ca}(0.044 / 100 \mathrm{mg})$ and energy sources $(\mathrm{g} / 100 \mathrm{~g})$ such as protein (1.26), carbohydrate (24.27), glucose (17.58) and fructose (18.20) (8).

In this study, percentages of spermatozoa with an intact acrosome were lower as compared to a previous study. Boer buck spermatozoa post thawing with an intact acrosome in fructose egg yolk and glycerol egg yolk extender were $63.92 \pm 1.65$ and $64.50 \pm 2.34$, respectively (30).

High percentages of incapacitated spermatozoa and spermatozoa with an intact acrosome in this study could be led by the effect of additional CF3 in TEY based extenders part of non enzymatic antioxidant protection system in liquid semen could be investigated by measuring Molandialdehyde (MDA) and superoxide dismutase (SOD) concentration in liquid semen. Some previous researchers explained that, MDA is the end 
product of lipid peroxidation in which it was very reactive and useful as biological marker to predict the level of oxidative stress (31) and the higher MDA concentration the more oxidative stress will be (32). If the concentration of oxidant is higher than concentration of antioxidant then oxidative stress will occur followed by increasing MDA concentration as a result of lipid peroxidation (33). In contrast, SOD is an antioxidant to neutralize the effect of superoxides and to protect cell from damage as a result of free radicals produced during metabolism process (34). In contrast, SOD (u/mL) concentration in TEY based extender $+0 \%, 4 \%, 5 \%$ and $6 \%$ CF3 increased from 9.6, 10.6, 10.8, 11.3 at 0 hour pre mixing with semen to 11.0, 16.5, 17.0, 17.4 and 13.0, 14.1, 14.3, 14.4 at 24 and 96 hours post mixing with semen. Therefore, additionaCF3 into TEY based extender improved protection performance of extender to neutralize the effect of peroxidation then spermatozoa will be protected from negative impact of free radicals (8). This hypothesis is supported by two previous reports that, antioxidant is also protect SOD activities so that optimized performance of the other antioxidant system (35; 36).

In the present study, pregnancy rate was obtained by using only preserved semen at $5^{\circ} \mathrm{C}$ for 96 hours Extended in TEY based extender $+6 \% \mathrm{CF} 3$ was $44.68 \%$. The result was obtained from single AI $48-50$ hours after sponges withdrawal. These conception rates were similar than those reported by some previous researchers. Pregnancy rates of intra cervical AI on Merino sheep at natural estrus, semen extender was tris egg yolk, sperm concentration was $200 \times 10^{6} / \mathrm{ml}$ stored at $5^{\circ} \mathrm{C}$ for 0,12 and 24 hours and the average temperature decreased at $0.25^{\circ} \mathrm{C} /$ minute, were $50.4 \%, 42.7 \%$ and $34.2 \%$, respectively. If semen stored for 12 hours and AI once after estrus detected, fix time AI at 48 and 54 hours and AI was performed twice at 48 and 54 hours after sponges withdrawal were $37.4 \%, 37.4 \%, 10.6 \%$ and $23.4 \%$ (13). The highest pregnancy rates $(70 \%-82 \%)$ of AI was obtained when using fresh semen (37), then decreased to $56.7 \%$ if that semen preserved at $5^{\circ} \mathrm{C}$ for 24 hours (38). Pregnancy rates when the sperm concentration was $150 \times 10^{6} / 0.1 \mathrm{ml}$ in straw preserved for $0,24,48$ and 72 hours, once AI intra cervical were 66, 40.4, 30 and 18.4\%, respectively (39). Pregnancy rate obtained of AI using liquid semen stored for 12 hours was $42.7 \%$ (Menchacaet al., 205). In addition, to obtain a good conception rate, liquid goat semen stored in refrigerator should not be kept more than 24 hours (26). In contrast with all of those previous reports, high pregnancy rate obtained from this study could be due to high quality extender as a result of additional CF3. Therefore, this study demonstrated that buck semen extended in TEY based extender $+6 \% \mathrm{CF} 3$ stored at $5^{\circ} \mathrm{C}$ for 96 hours could be used and obtained fair pregnancy rates.

\section{Conclusion}

Additional CF3 into TEY based extender increased the ability of extender to preserve incapacitated and intact acrosome of sperm. The storage of buck semen up to 96 hours at $5^{\circ} \mathrm{C}$ in TEY based extender $+6 \% \mathrm{CF} 3$ via fix time $\mathrm{AI}$ results in acceptable pregnancy rates. However, protection mechanisms of $\mathrm{CF} 3$ to preserve liquid semen quality is a subject to find out and to overcome a limitation of an existing extender to establish a new proven extender for high pregnancy rates of buck semen..

\section{Acknowledgments}

We are grateful to Prof. Mahyuni for critical reading of this manuscript and valuable correction of English in the manuscript.

\section{References}

[1] E.P. Cunningham, Breeding program for improved dairy production in tropical climates. In Animal Husbandry in Warm Climates. Proceedings of the International Symposium on Animal Husbandry in Warm Climates. Viterbo, Italy. Pudoc Wageningen, 1991, $39-47$.

[2] J.S.F. Barker, Animal breeding for tolerance to adverse environment. In Sustainable Animal Production and the Environment. Procceding of the $7^{\text {th }}$ AAAP Animal Science Congress, Bali, Indonesia, (1), 1994, 29-39.

[3] G.H. Shackle, B. Kyle, R.P. Littlejohn, Factors influencing the success of a large scale artificial insemination ptogremme in sheep, Procceding New Zealand Society of Animal Production, (50), 1990, 427-430.

[4] J. Gill, N. Lundeheim, L. Soderquist, H. Rodriguez-Martinez, Influence of extender, temperature and addition of glycerol on postthaw sperm parameters in ram semen, Theriogenology, (59), 2003a, 1241-55.

[5] T. Matsuoka, H. Imai, H. Kohno, Y. Fukui, Effects of bovine serum albumin and trehalose in semen diluents for improvement of frozen-thawed ram spermatozoa. J. Reprod. Dev. (52), 2006, 675-83.

[6] R. Vishwanath, P. Shannon, Storage of bovine semen in liquid and frozen state. Animal Reprododuction Science, (62), 2000, 2353.

[7] G. Wang, H. Wang, Y. Song, C. Jia, Z. Wang, H. Xu, Studies on anti-HSV effect of Ficus carica leaves, Zhong Yao Cai, (27), 2004, 754-768.

[8] L.A. Zaenuri, T. Susilawati, S.B. Sumitro, S. Wahyuningsih, Effects of additional Crude Extract of Fig Fruit (Ficus carica L) Into Tris Egg Yolk Based Extender on Quality of Buck Semen, Journal of Biology, Agriculture and Healthcare, (4) 9, $2014,21-27$.

[9] J. Morton, 1987. Fruits of warm climates. (Book. Fl. Ig. Miami, 2005), 47-50.

[10] L.A. Zaenuri, T. Susilawati, S.B. Sumitro, S. Wahyuningsih, The prospectus of local fig fruit (Ficus glumerata R) extract to preserve goat sperm motility, J Kedokteran Hewan, 7 (1), 2013, 26-28. (Article in Indonesian with an English abstract).

[11] G. Evans and W.M.C. Maxwell, Salamon's artificial insemination of sheep and goats, Sydney, NSW, Australia, (University Press, 1989). 
[12] W.M. Mollineou, A.O. Adogwa and G.W. Garcia, Liquid and frozen storage of Agouti (Dasyprocta leporina) semen extender with UHT milk, unpasteurized coconut water and pasteurized coconut water, Veterinary Medicine International, 2011, 1-5.

[13] A. Menchaca, A Pinnezak, D Queirolo, Strorage of ram semen at $5^{\circ} \mathrm{C}$ : effects of preservation period and timed artificial insemination on pregnancy rate in ewes. Anim. Reprod. Sci., 2 (3), 2010,195-198.

[14] S.M.H. Andrabi, Factors affecting the quality of cryopreserved buffalo (Bubalus bubalis) bull spermatozoa. Reproduction in Domestic Animal, 2008, (in press).

[15] R.S. Jeyendran, H.H. Van Der Ven, M. P. Pelaez, B. G. Crabo and L.J.D. Zaneveld, Development of an assay to assess the functional integrity of the human sperm membrane and its relationship to other semen characteristics. Journal of Reproduction and Fertility, (70), 1984, 219-228.

[16] T. Susilawati, Spermatology. Malang. Indonesia. (University of Brawijaya Press, 2012), Tex Book in Indonesian.

[17] S. B. Sumitro and T. Susilawati, Pedoman Penggunaan Mikroskop Multisistim dan Inverted. (Universitas Brawijaya. Malang Press, Indonesia, 1998).

[18] K. Anderson, J. Aamdal, J.A. Fougner, Intrauterine and deep cervical insemination with frozen semen in sheep, Zuchthygiene, (8), 1997, 113-118.

[19] S. Kukovics, E. Gyoker, T. Nemeth and E. Gergatz, Artificial insemination of Sheep-Possibilities, Realities and Techniques at the Farm Level, In M. Manafi, Artifial Insemination in Farm Animals,. In Tech. India. A free on line edition at www.intechhopen.com. 2011, 27-50.

[20] R.G.D. Steell and J.H. Torie (1980). Principals and Procedures of Statistics. Mc Graw Hill, Inc, London.

[21] R.L. Ax, M.R. Dally, B.A. Didion, R.W. Lenz, C.C. Love, D.D. Varner, B. Hafez, M.E. Bellin, Artificial Insemination, In E.S.E. Hafez (Ed), Reprodustion in farm animals 7th, (Iowa, USA: Blackwell, 2008), 376-389.

[22] J.P.C. Greyling and J.A.N. Grobbelaar, Seasonal variation in semen quality of Boer and Angora goat rams using different collection techniques, South African Journal of Animal Science, 13(4), 1983, 250-252.

[23] H. Paulenz, L. Söderquist, T. Ådnøy, O.H. Fossen, K. Andersen Berg, Effect of milk- and TRIS-based extenders on the fertility of sheep inseminated vaginally once or twice with liquid ram semen, Theriogenology, (60), 2003, 759-766.

[24] A.S. Alghamdi, B.J Funnell, S.L. Bird, G.C Lamb, A.K Rendahl, P.C Taube, D.N Foster, Comparative studies on bull and stallion seminal DNase activity and interaction with semen extender and spermatozoa, Animal Reproduction Science, (121), 2010, 249-258. doi:10.1016/j.anireprosci.

[25] S. Saraswat, R. Priyadharsini, S.K. Jindal, S. Yadav, N. Ramachandran, S.D. Kharche and A.K. Goel, Effect of Antioxidants Supplementation at RefrigerationTemperature on Sperm Motion Characteristics and Membrane Integrity of Sirohi Buck Semen, Journal of Physiology and Pharmacology Advance, 2(1), 2012, 77-86.

[26] I. Udeh and B. Oghenesode, Effects of Type of Extender and Storage Conditions on the Motility of Goat Spermatozoa, International Journal of Animal and Veterinary Advances 3(5), 2011, 282-286.

[27] A. Anghel, S. Zamfirescu, C. Dragomir, D. Nadolu, S. Elena, B. Florica, The effects of antioxidants on the cytological parameters of cryopreserved buck semen, Romanian Biotechnological Letters, (15), 2010, 3. Supplement.

[28] Y.Y. Hsieh, C.C. Chang, C.S. Lin, Seminal malondialdehyde concentration but not glutathione peroxidase activity is negatively correlated with seminal concentration and motility, International Journal of Biological Science, ISSN 1449-2288 www.biolsci.org. 2(1), 2006,23-29.

[29] U.G. Ari, A. Daşkin, Freezing of Washed Angora Goat Semen with Extenders Added Bull or Ram Seminal Plasma, Kafkas Univ Vet Fak Derg, 16 (2), 2010, 233-237.

[30] S.W. Naing, A.W. Haron, M.A.K. Goriman, R. Yusof, Md. Z.A. Bakar, K. Sarsaifi, M.M. Bukar, M. Thein, T. Kyaw and M.M. San, Effect of Seminal Plasma Removal, Washing solutions, and Centrifugation Regimes on Boer Goat Semen Cryopreservation, Pertanika J. Trop. Agric. Sci. 34 (2), 2010, 271 - 279.

[31] L.L. DeZwart, J.C.H. Meerman, J.N.M. Commandeur, N.P.E. Vermulen, Biomarker of free radical damage. Application in experimental animals and humans, Free Rad. Biol. Med, (26), 1998, 202-26.

[32] D. Stroncek, J.L. Procter, J. Johnson, Drug Induced Hemolysis: Cefotetan-dependent hemolytic anemia. An Acute Intravascular Immune Transfusion Reaction. American Journal Hematology, 64(1), 2000, 67-70.

[33] M.A. Short, Linking the Sepsis Triad of Inflammation, Coagulation, and Suppressed Fibrinolysis to Infants, Advance Neonatal Care, (5), 2004, 258-73.

[34] J. Kelvin, A. Davias and A.P. William, The evolution of free radical biology \& medicine a 20-years history. Free Radical Biology \& Medicine, 39(10), 2005,1263-1290.

[35] M.R. Luck, I. Jeyaseelan and R.A. Scholes, Ascorbic acid and fertility (Minireview), Biology Reprododuction, (52), 1995, $262-266$.

[36] M.T. Beconi, C.R. Francia, N.G. Mora and M.A. Affranchino, Effect of natural antioxidants on frozen bovine semen preservation, Theriogenology, (40), 1993, 841-851.

[37] A. Donovan, J.P. Hanrahan, E. Kummen, P. Duffy, M.P. Boland, Fertility of the ewe following cervical insemination with fresh or frozen-thawed semen at natural or synchronized oestrus, Animal Reproduction Science, (84), 2004, 359-368.

[38] D. Fernandez-Abella, M.O. Preve, N. Villegas, Insemination time and diluting rate of cooled and chilled ram semen affects fertility, Theriogenology, (60), 2003, 21-26.

[39] S. Salamon, W.M.C. Maxwell and J.H. Firth, Fertility of ram semen after storage at 5 ${ }^{\circ}$ C, Animal Reproduction Science, (2), 1979, 373-385. 